\title{
DE LA LEGITIMACIÓN DE UNA "JOYA" A LA CRÍTICA DE LOS GASTOS ELECTORALES: LA POLÍTICA ECONÓMICA DEL PRIMER GOBIERNO DE LULA EN LOS EDITORIALES DE O ESTADO DE S. PAULO
}

ARIEL ALEJANDRO GOLDSTEIN Universidad de Buenos Aires (UBA) Buenos Aires, Argentina E-mail: arielgoldstein@hotmail.com 
DE LA LEGITIMACIÓN DE UNA “JOYA” A LA CRÍTICA DE LOS GASTOS ELECTORALES: LA POLÍTICA ECONÓMICA DEL PRIMER GOBIERNO DE LULA EN LOS EDITORIALES DE O ESTADO DE S. PAULO'.

Resumen: Este trabajo se propone comprender las variaciones ideológicas del periódico $O$ Estado de S. Paulo referidas a la política económica del primer gobierno de Lula (2003-2006). A partir del análisis de sus editoriales durante tres períodos críticos: la Reforma de la Jubilación, el "mensalão" y las elecciones de 2006, procuraremos identificar el paso en la percepción del periódico de una legitimación de la austeridad fiscal a la crítica de la política económica por sus gastos excesivos, así como por el “electoralismo" propio del programa Bolsa Familia.

Palabras clave: economía, Lula, populismo, prensa paulista, Estadao

\section{DA LEGITIMAÇÃO DE UMA “JOIA” PARA A CRÍTICA DOS GASTOS ELEITORAIS: A POLÍTICA ECONÔMICA DO PRIMEIRO GOVERNO LULA NOS EDITORIAIS DE O ESTADO DE S. PAULO}

Resumo: Este trabalho tem o propósito de compreender as variações ideológicas do jornal $O$ Estado de S. Paulo relativas à política econômica do primeiro governo Lula (2003-2006). Partindo da análise de suas editoriais durante três períodos críticos: a Reforma da Previdência, o "mensalão" e as eleições de 2006, procuraremos identificar a mudança na percepção do jornal desde uma legitimação da austeridade fiscal, para a crítica da política econômica pelos gastos excessivos, assim como pelo "eleitoralismo" do programa Bolsa Familia.

Palavras chave: economia, Lula, populismo, imprensa paulista, Estadao

FROM THE LEGITIMATION OF A "JEWEL" TO THE CRITIC OF THE ELECTORAL COSTS: THE ECONOMIC POLITICS OF LULA'S FIRST RULE IN THE EDITORIALS OF O ESTADO DE S. PAULO

Abstract: The aim of this work is to comprehend the ideological variations of the newspaper $O$ Estado de S. Paulo regarding the economic politics of Lula's first rule (2003-2006). By analyzing their editorials during three critical periods -the Retirement System Reform, the "mensalão" and the elections of 2006- we pretend to identify the transformation in the newspaper's perception, from the legitimation of the fiscal austerity to his subsequent critic of the economical politics for their excessive costs, and for the "electioneering" of the Bolsa Familia program.

Key words: economy, Lula, populism, paulista press, Estadao

1 Agradezco a Gerardo Aboy Carlés y Fernando Azevedo por las indicaciones referidas para la elaboración de este trabajo. 


\section{MEDIOS DE COMUNICACIÓN Y DEMOCRATIZACIÓN SOCIAL DEL PODER POLÍTICO}

La llegada en enero de 2003 al Palacio del Planalto de un líder de origen popular por el Partido de los Trabajadores (PT), supuso un importante recambio en la composición de las elites políticas brasileñas ${ }^{2}$. En una sociedad marcada por desigualdades estructurales, su acceso a la presidencia implicó una democratización social del poder político, por primera vez representado en la figura de un presidente que había conocido la experiencia de la miseria (Singer, 2012). Esta democratización social del poder político, así como el recambio que se produjo en las elites gubernamentales, condensaron en la figura de Lula tanto las expectativas de sus partidarios, como el rechazo y los cuestionamientos de sus opositores.

El nuevo proceso político que comenzaba sería percibido con desconfianza por ciertos grupos tradicionales de los sectores dominantes. Encontró opositores entre las elites políticas tradicionales, en ciertos grupos empresariales radicados en San Pablo, así como en medios de comunicación de importante audiencia. Una parte de los medios de comunicación, concentrados en unos pocos grupos familiares que detentan la propiedad cruzada de los principales periódicos, revistas y canales de televisión (Azevedo, 2008) ejercerían una importante posición en representación de estos intereses.

A nivel teórico, sostendremos una perspectiva que supone que los periódicos resultan actores políticos que van modificando sus posiciones según las distintas coyunturas, cambios en el mercado de audiencias y los alineamientos de otros actores políticos. De acuerdo a nuestro enfoque, existen tensiones entre la pretensión de los periódicos de influir como actores políticos y la necesidad de lucrar en el mercado de audiencias (Borrat, 1989), como dos lógicas que definen su actuación en un contexto determinado. Teniendo en cuenta estos aspectos, nuestro propósito reside en focalizar el análisis en el discurso editorial sobre la política económica de un periódico estrechamente vinculado a los grupos tradicionales de poder, O Estado de $\mathrm{S}$. Paulo, en un momento de democratización del país.

Para ello, desarrollaremos primero el marco teórico y la delimitación de nuestro objeto de estudio, incluyendo referencias sobre las características

2 Según el historiador Lincoln Secco (2011), en su reciente Historia do PT, el Partido de los Trabajadores resulta, dentro de las fuerzas políticas brasileñas, aquel con mayor composición parlamentaria de trabajadores dentro de sus filas. 
ideológicas de O ESP en tanto periódico. Posteriormente, analizaremos los encuadramientos del matutino con respecto a la política económica del primer gobierno de Lula, así como las definiciones ideológicas del periódico sobre este aspecto. Para finalizar, elaboraremos una conclusión sobre el material empírico relevado que nos permita comprender los encuadramientos dominantes y los trazos característicos de la ideología del periódico frente a la política económica impulsada por el gobierno brasileño.

\section{MARCO TEÓRICO PARA EL ANÁLISIS: ENCUADRAMIENTOS, IDEOLO- GÍAS Y ANÁLISIS DEL DISCURSO}

Para nuestro estudio sobre los editoriales de O ESP, hemos definido, como señala Porto (2002), la conveniencia de adoptar un enfoque que combine un análisis cuantitativo y cualitativo, con el propósito de detectar tanto las regularidades y repeticiones estadísticas, como las especificidades discursivas desplegadas en los editoriales del periódico en cada coyuntura.

Es por ello que, desde el punto de vista de nuestro marco teórico, recurriremos a dos tipos de vertientes para el análisis. Desde lo cuantitativo, un papel organizador de nuestro trabajo lo cumplirá la teoría de los encuadramientos de Gamson y Mogdiliani (1989), la cual define un encuadramiento como una idea central que organiza y provee sentido a los acontecimientos, defendida por grupos sociales que pretenden ejercer influencia en la esfera pública, sugiriendo "qué es un tema". A partir de esta idea se seleccionan y tornan relevantes determinados aspectos de una realidad para promover definiciones, causas y consecuencias de los eventos, y apelar a principios para promover determinados cursos de acción (Entman, 1993, citado en Londoño, 2011).

Concibiendo a los encuadramientos como patrones de interpretación, que tienden a sedimentar contextos de significación con una productividad propia que se va reforzando, se evidencian sus referencias comunes con el análisis semiológico de Barthes (2004), que se estructura en torno a la noción de mito. Esta vinculación nos permite añadir la pertinencia a nivel cualitativo de los desarrollos sobre las ideologías formulados por Ansart y Barthes.

Según Barthes (2004), el mito constituye un sistema de comunicación, un modo de significación y una forma. Para el autor, la función del mito no es ocultar o hacer desaparecer, sino deformar el sentido de las primeras 
significaciones (Barthes, 2004). El autor aborda así las productividades que involucran el juego semiológico característico del mito:

\begin{abstract}
"Al pasar de la historia a la naturaleza, el mito efectúa una economía: consigue abolir la complejidad de los actos humanos, les otorga la simplicidad de las esencias, suprime la dialéctica, cualquier superación que vaya más allá de lo visible inmediato, organiza un mundo sin contradicciones puesto que no tiene profundidad, un mundo desplegado en la evidencia, funda una claridad feliz: las cosas parecen significar por sí mismas" (Barthes, 2004; 239).
\end{abstract}

Otra definición importante para el abordaje cualitativo de nuestro análisis supone el concepto de ideología política de Ansart. El autor señala que

\footnotetext{
"una ideología política se propone señalar a grandes rasgos el sentido verdadero de los actos colectivos, trazar el modelo de la sociedad legítima y de su organización, indicar simultáneamente a los detentores legítimos de la autoridad, los fines que la comunidad debe proponerse y los medios para alcanzarlos" (Ansart, 1983; 28).
}

Para este autor, el discurso propio de las ideologías políticas se caracteriza por una continua reactivación de los valores que jerarquizan y diferencian a los sectores sociales. En este sentido, la ideología se expresa en "discursos prácticos que se conforman a las exigencias de la pareja legitimación/ invalidación" (Ansart, 1983; 31). La concepción de la ideología elaborada por Ansart implica como características la detención de la lucidez dialéctica y una naturalización del pensamiento. De esta manera y, según la perspectiva de los autores, el discurso ideológico (Ansart) y el juego semiológico del mito (Barthes), son capaces de producir una desfiguración de las relaciones sociales que sostienen la dominación.

Definidos los recursos teóricos para la realización de nuestros análisis cualitativo y cuantitativo, pasaremos a una descripción de la metodología empleada para la selección de nuestro objeto de estudio y las definiciones pautadas para el recorte realizado sobre el mismo.

\title{
OBJETO DE INVESTIGACIÓN Y METODOLOGÍA
}

O Estado de S. Paulo ha sido elegido por resultar uno de los periódicos de mayor tirada a nivel nacional, a pesar de la carencia de periódicos de circulación nacional en el sistema de prensa brasileño. Tanto la Folha de S. Paulo 
como O Estado de S. Paulo tienen la mayor tirada entre los periódicos brasileños. Según el Instituto Verificador de Circulaciones, Folha posee 294.498 ejemplares diarios promedio en 2010 y O ESP posee 236.369. Por lo tanto, ambos se encuentran entre los periódicos de mayor circulación.

Este trabajo está dedicado a estudiar los editoriales del periódico O Estado de S. Paulo referidos a la política económica durante tres diferentes coyunturas: la Reforma de la Jubilación, el mensalão y las elecciones presidenciales de 2006, durante las cuales el periódico fue cambiando sus definiciones editoriales, aspirando a comprender estos cambios de definición.

Los tres períodos de nuestro análisis abarcaron 572 días, con la siguiente delimitación 3 :

a) primer período, del 01/05/2003 al 27/11/2003, 211 días

b) segundo período, del 14/05/2005 al 09/11/2005, 179 días

c) tercer período, 01/05/2006 al 29/10/2006, 182 días

1.716 editoriales fueron leídos para seleccionar aquellos que serían objeto de análisis, que resultaron, en el caso de este trabajo, 91 editoriales correspondientes a la política económica. ${ }^{4}$ Estos últimos fueron clasificados como relevantes de acuerdo a la teoría de los encuadramientos y las categorías emergentes de su lectura. De estos 91 editoriales analizados en total, 17 correspondían al primer período de la Reforma de la Jubilación, 26 al pe-

3 Para la selección de los editoriales, fueron privilegiados aquellos que hacen referencia a la dimensión del poder: esto es, referidos a las instituciones gubernamentales y los liderazgos que detentan una representación máxima en aquellas instituciones. Al delimitar nuestras categorías de clasificación a determinados encuadramientos, consideramos que expresaban las temáticas centrales impulsadas por el periódico en su papel de formador de opinión pública durante el período. Para el análisis de los datos, se definió clasificar a cada editorial en una sola categoría/encuadramiento, definido en función de su "temática dominante" (Miguel y Coutinho, 2007), referenciándose en última instancia al título del editorial para la definición de la "temática dominante" cuando existiera más de un encuadramiento manifiesto en el editorial. Esta última definición se realizó considerando en un primer conteo que la amplia mayoría de los editoriales podían ser clasificados en un solo encuadramiento, así como pensando en una clasificación cuantitativa que pudiera oficiar de orientación para el análisis textual cualitativo, centrado en las definiciones de ideología política del periódico.

4 Este trabajo representa una selección parcial de una investigación más extendida, referida a mi Tesis de Maestría, que abarca 5 aspectos de la cobertura de O ESP sobre el primer gobierno Lula: liderazgo presidencial, PT, movimientos sociales, política externa y economía (aquí tratada). Para la lectura del análisis completo, consultar Goldstein, 2013. 
ríodo del denominado Mensalão, y 48 al período de las elecciones presidenciales de 2006. Los editoriales fueron agrupados en encuadramientos que fueron definidos de forma emergente a partir de su lectura, identificando las temáticas que sobresalían en repetición y relevancia por parte del periódico.

Dentro del área de vacancia que este artículo pretende colmar, se puede mencionar la Tesis de Maestría de Nunomura (2012), que investiga el desempeño durante el escándalo del "mensalão" de la revista Veja y el periódico Folha de S. Paulo. El autor llega a la conclusión de que la revista Veja actuó como un medio de oposición al gobierno Lula durante este escándalo político, mientras que la Folha de S. Paulo, si bien se comportó de forma crítica hacia el gobierno, lo hizo de forma equitativa con el tratamiento dispensado al poder político durante el gobierno de Fernando Henrique Cardoso. También es posible mencionar el estudio de las relaciones entre el discurso de la oposición y el de la revista Veja durante el primer gobierno de Lula, el cual ha sido realizado por Menezes (2008).

En este sentido, dentro de los medios de prensa de mayor circulación en Brasil, O ESP resulta un medio a ser investigado durante el período para complementar estos análisis. Según Conti

\footnotetext{
"Fundado en 1875 por un grupo de republicanos, con el nombre de A Província de S. Paulo, desde 1891 el periódico era dirigido por la familia Mesquita. En sus más de cien años de existencia, el Estado se envolvió a fondo en la historia política del país, defendiendo las convicciones liberales de la familia propietaria y reflejando los intereses de un sector poderoso del empresariado y de la clase media paulistas." (Conti, 1999; 612).
}

Una característica a considerar de O ESP señalada por Prado y Capelato (1980) remite a su ideología liberal-conservadora y su defensa del orden social, considerando como subversivo aquello que excede su cosmovisión de naturalización de las jerarquías (Prado y Capelato, 1980). En este punto, resaltan "la perspectiva de clase dominante que se traduce muy claramente en la visión elitista y conservadora de la sociedad por parte del periódico" (Prado y Capelato, 1980; 21).

Explicitadas las definiciones metodológicas de la investigación y las características ideológicas del periódico a analizar, pasaremos ahora a una breve justificación y descripción de las coyunturas de análisis seleccionadas. 


\section{TRES PERÍODOS: SELECCIÓN Y JUSTIFICACIÓN}

La aspiración de nuestra investigación apunta a reconocer las características que asumió la percepción del periódico relativa a la política económica del gobierno en tres coyunturas de polarización política entre actores de la sociedad brasileña. Estas coyunturas han sido elegidas por expresar las tensiones centrales y alineamientos asumidos por los actores políticos durante este gobierno. En este sentido, las coyunturas a analizar serán: la Reforma de la Jubilación, que hemos considerado abarca desde Mayo de 2003 hasta Diciembre de 2003, el denominado mensalão, que hemos delimitado entre Mayo de 2005 y Noviembre de 2005, así como el período correspondiente a las elecciones de 2006, que hemos delimitado entre Mayo de 2006 y Octubre de 2006.

Pretendiendo realizar una descripción de las coyunturas seleccionadas, podemos señalar que la Reforma de la Jubilación fue una importante coyuntura crítica o "momento traumático" (Sader, 2010) que se desarrolló durante el primer gobierno de Lula, al resultar el primer acontecimiento donde se expresaron en intensidad las contradicciones del proceso político brasileño. El comienzo de la presidencia de Lula se inició con tensiones al interior del Partido dos Trabalhadores, entre la tendencia del campo mayoritario, hegemónica al interior del PT, y las tendencias del ala izquierda del partido.

A partir del ingreso al Congreso, en mayo de 2003, del proyecto de Reforma de la Jubilación, emergieron las tensiones al interior del PT entre la dirección partidaria y las tendencias de izquierda del partido, representadas estas últimas por la resistencia exhibida por parte de ciertos diputados a acatar las resoluciones partidarias referidas a votar en favor de la Reforma de la Jubilación.

Esta reforma suponía -en el contexto de crisis económica en que se encontraba Brasil en 2003- la pretensión de establecer recortes a los beneficios de jubilación integral de los que gozaban funcionarios y empleados públicos, que les permitían recibir una jubilación equivalente al salario percibido como funcionarios.

El desarrollo de estos conflictos se dirimió con la expulsión de dirigentes pertenecientes a la izquierda partidaria, dadas las tensiones que comenzaron a producirse con motivo de la votación de la Reforma en el parlamento. La Reforma contó en la votación con el apoyo de siete parlamentarios del PFL y seis del PSDB. De este modo, el 27 de noviembre, el texto principal de 
la reforma fue aprobado en el Senado con 13 votos de la oposición 5 .

En el caso de la segunda coyuntura, la crisis política del "mensalão" surgió a partir de las tensiones que se produjeron al interior de la heterogénea alianza que el PT había compuesto a nivel parlamentario para garantizar la "gobernabilidad" (PL, PPS, PTB y PDT). En mayo de 2005, la Revista Veja publicó la transcripción de un video donde se acusaba al diputado de la coalición gubernamental Roberto Jefferson del Partido Laborista Brasileño (PTB), de estar detrás del desvío de dinero en la empresa pública de Correos. El entonces diputado, que habría intuido que no recibiría en este contexto apoyo del Palacio del Planalto (Pilagallo, 2012), decidió en consecuencia realizar una serie de denuncias que tuvieron un efecto explosivo. En una entrevista el 6 de junio a la Folha de S. Paulo, acusó al PT de estar pagando una mensualidad a los parlamentarios de la base aliada a cambio de apoyo al gobierno de Lula en el Congreso. La conmoción que la denuncia de estos escándalos produjo en la opinión pública tuvo por efecto: una importante erosión del capital político del gobierno, un incremento en la polarización entre el gobierno y la oposición, así como la apertura de varias Comisiones Parlamentarias de Investigación ( $\mathrm{CPI}$ ) encargadas de investigar los acontecimientos en el Congreso. Es preciso agregar que esto produjo al interior del PT una crisis interna que llevó al partido al borde de la fractura ${ }^{6}$ e impactó a nivel simbólico, dado que el PT había producido una diferencia desde su fundación con respecto al resto del sistema partidario al presentarse como defensor de la "ética en la política".

La crisis del Mensalão, que redujo la popularidad del presidente y, sobre todo, la propia del Partido dos Trabalhadores, radicalizó las posiciones de los líderes de oposición. Finalmente, tras meses de crisis política, con la elección el 28 de septiembre de Aldo Rebelo de la coalición gubernamental (Partido Comunista de Brasil) como presidente de la Cámara de Diputados, se originó un contexto de mayor estabilidad para el gobierno brasileño. ${ }^{7}$

5 Folha de S. Paulo, 27/10/2003. Sobre esta coyuntura, hemos producido una selección que comienza el 1 de mayo 2003 y termina el 27 de noviembre del mismo año. La misma fue realizada tomando como comienzo el día 30 de abril de 2003, durante el cual Lula entregó al Congreso el proyecto de Reforma de la Jubilación acompañado de los 27 gobernadores del país, hasta la aprobación de la reforma en el Senado el 27 de noviembre, luego de una primera aprobación en la Cámara de Diputados.

6 Carta Capital, 20/07/2005, pág. 29.

7 Para la delimitación del período de análisis del mensalão seguiremos el criterio definido 
Con respecto al tercer período, correspondiente a las elecciones de 2006, resultó éste un momento que cristalizaría la disputa política existente entre el candidato del Partido de la Socialdemocracia Brasileña (PSDB), Geraldo Alckmin y la continuidad del proyecto petista representado por Lula.

En este contexto generalizado de acusaciones de corrupción al partido de gobierno, el PSDB eligió como candidato a la presidencia en 2006 a Geraldo Alckmin, quien se presentaba a sí mismo con el discurso de la "eficiencia" y la "transparencia" como valores constitutivos. Para estas elecciones, Lula apeló al clivaje Estado / privatizaciones, señalando las posibilidades, en caso de un triunfo de Alckmin, de un retorno de las privatizaciones realizadas durante el gobierno de FHC. El candidato petista, a su vez, se presentaba como el defensor de una recuperación de la intervención estatal que tenía importantes efectos positivos para los sectores sociales de más baja renta (Goldstein y Comellini, 2012).

Sin embargo, a pesar de las acusaciones contra el gobierno, señala Sader (2013) que:

\begin{abstract}
"Las inversiones en políticas sociales comenzaron a generar resultados, cambiando la base fundamental de apoyo social del gobierno para los sectores más pobres y para las regiones más relegadas del país. Frente a la posibilidad de que Lula desencadenara una gran movilización popular en defensa del gobierno y de su mandato, la oposición retrocedió y jugó todo en la posibilidad de sangrar al gobierno de los recursos en el Congreso y derrotarlo en las elecciones de 2006. Pero los efectos de las políticas sociales permitieron a Lula ser reelegido, consolidando un nuevo tipo de apoyo popular al gobierno, paralelo a la recuperación del crecimiento. Esa tendencia tuvo que ver directamente con el cambio del equipo económico del gobierno y de sus prioridades generales, que
\end{abstract}

previamente en la tesis de Eduardo Nunomura (2012), dedicado al análisis del mensalão en la Folha de S. Paulo y la revista Veja, que abarca desde el 14 de mayo al 9 de noviembre de 2005. El autor señala: "Aunque el escándalo del mensalão haya tenido nítidamente un comienzo, una fecha inaugural, éste no parece tener un fin. Sin embargo, para esta investigación, era necesario crear una delimitación justificable. Singer sugiere parámetros lógicos, al afirmar que el mensalão tendió 'un cerco político-mediático al presidente, dejándolo a la defensiva por cerca de seis meses' (Singer, 2012; 52). El autor recuerda, con 'señales de los medios', que la fase aguda del escándalo se inició con el reportaje de Veja que comenzó a circular el 14 de mayo de 2005 y terminó con la entrevista presidencial en el programa Roda Viva, de la TV Cultura de San Pablo, el 7 de noviembre del mismo año. Se estableció, así, que el período de análisis de la cobertura sobre el mensalão quedaría limitado a esos seis meses, del 14 de mayo al 9 de noviembre." (Nunamura, 2012; 77). 
abandonó la orientación conservadora de la política económica, sustituyéndola por un modelo de desarrollo que articulaba estructuralmente crecimiento económico con políticas de distribución del ingreso." (Sader, 2013; 140). ${ }^{8}$

A partir del análisis de los editoriales durante los tres períodos reseñados, comenzaremos a adentrarnos en las definiciones de O ESP sobre la política económica.

\section{DE LA LEGITIMACIÓN A LA “JOYA DE UN GOBIERNO SIN CORONA" A LA CRÍTICA DE LOS GASTOS ELECTORALES}

La política económica del primer gobierno Lula atravesaría dos etapas. Los inicios del gobierno estuvieron caracterizados por la ortodoxia económica del ministro Antonio Palocci, acorde a los condicionamientos que experimentaba el gobierno por parte de los principales actores económicos para sostener el rumbo definido desde la presidencia de Fernando Henrique Cardoso. Hacia fines de este mandato, con la renuncia de Palocci ${ }^{9}$ y la asunción de Guido Mantega, tendría lugar una orientación de carácter más desarrollista, que presentaría una mayor afinidad con las expectativas del $\mathrm{PT}^{10}$.

En el caso de las definiciones de O ESP respecto de las cuestiones económicas, Moraes (1991) señala que éste posee

8 Como criterio para la selección de los editoriales del período hemos delimitado como inicio la estatización de Petrobras en Bolivia el 1 de Mayo, por la politización de la campaña y el debate que generó en torno a la política externa, hasta el fin de la campaña electoral que terminó con la reelección presidencial de Lula da Silva el 29 de octubre, cuando se dirime la 2da vuelta de las elecciones presidenciales de 2006.

9 Lula, que tenía una importante apreciación por el trabajo del Ministro de Fazenda Antonio Palocci, se vio obligado a prescindir de su cargo cuando a partir del 20 de agosto de 2005, comenzaron a surgir acusaciones a Palocci que remitían a su época como intendente de Ribeirão Preto que lo vinculaban con escándalos de corrupción, así como fue acusado de haber asistido a casas de lobistas en Brasilia.

10 Entrevista a Sergio Fausto, director del Instituto Fernando Henrique Cardoso, San Pablo, 10/04/2012. Fausto señala que "Con la salida de Antonio Palocci, el gobierno se alejó de la línea más liberal adoptada en el primer mandato. Tal cambio no significó una ruptura con la política económica heredada del gobierno FHC y mantenida por Palocci (...) el cambio se dio menos en el manejo de la política económica y más en el papel atribuido al Estado en la regulación y el fomento de la economía." (Fausto S., 2012; 539). "El cambio del péndulo en dirección a una posición más 'estatista' representó un reencuentro del gobierno con el pensamiento dominante del PT sobre el papel del Estado en el desarrollo económico." (Fausto S., 2012; 540). 
“una posición ideológica radical (...) manifiesta en la opción neoliberal (o neoconservadora), en que la economía pasa a ser el centro de la organización del país, predominando sobre el orden social. (...)" (Moraes, 1991:173)." (citado en Bezerra de Paiva, 2006; 29).

Considerando esto último, no resulta difícil comprender que el cambio en la orientación de la política económica que tendría lugar hacia fines del primer mandato de Lula produciría una mutación en las apreciaciones económicas del periódico. Estas apreciaciones se enmarcarían en la evaluación de O ESP sobre el proceso político general, que hemos caracterizado en otro trabajo como el paso de una inicial expectativa a la confrontación (Goldstein, 2013).

Especialmente durante el primer período, tendrían relevancia las cuestiones económicas, pues estas atravesaban, hacia derecha e izquierda, el debate sobre la significación del gobierno Lula. ${ }^{11}$ Los principales actores económicos aspiraban a condicionar al gobierno a preservar la estabilidad económica suscripta en la Carta al Pueblo Brasileño de 2002 e iniciada con el Plan Real instrumentado por Fernando Henrique Cardoso (O ESP actuaba como vocero de estos sectores). La izquierda petista y los movimientos sociales centraban el debate en la presencia o no de una coherencia entre la práctica gubernamental del gobierno Lula y su trayectoria de izquierda.

Durante este primer período, de los 17 editoriales que hemos identificado como correspondientes a la temática económica, 12 (70\%) estarían abocados a plantear la distinción entre una política responsable de austeridad fiscal vs. otra irresponsable y aventurera, y 5 (30\%) estarían referidos a señalar la necesidad de renovar el acuerdo con el Fondo Monetario Internacional para preservar la estabilidad y la "austeridad fiscal". En términos generales, una característica del periódico en este período resultaría el elogio hacia el rumbo ortodoxo de la política económica asumido por el gobierno, en sintonía con las elecciones de 2002.

El periódico exigiría, a través de sus editoriales, sostener lo que denominaba como una política económica responsable, capaz de preservar la "estabilidad":

“1) la tasa de interés es un valor importante y un instrumento fundamental de la política económica. El voluntarismo es una forma extremadamente peligrosa de manejar ese instrumento; 2) Una campaña contra el Banco Central -porque es eso lo se viene predicando- es apenas un preludio de campañas igualmente destruc-

11 Entrevista a André Singer, San Pablo, 12/04/2012. 
tivas contra cualquier política económica responsable-; 3) Los miembros del gobierno y los líderes del gobierno en el Congreso deben ser extremadamente cuidadosos al atender asuntos delicados como la tasa de interés y el cambio. Cuando son incapaces de ese cuidado, crean riesgos no solo para la política oficial, sino también para el País"12

La definición de O ESP, presente desde el inicio, sería aconsejar una prudencia conservadora en la administración de la economía, para prevenir los riesgos nacionales que podrían producirse en caso de actuarse de forma "irresponsable".

El periódico adoptaba una actitud de legitimación hacia las políticas desarrolladas por Palocci, a la vez que advertía sobre los riesgos de enfocar el crecimiento atentando contra la estabilidad económica:

\begin{abstract}
"Tan estimulante como los nuevos números -y tal vez más- es la disposición mostrada por el ministro de Fazenda, responsable principal por el severo ajuste impuesto a la economía en el primer semestre. Al decir que una página fue cambiada en la política económica, usó el mismo énfasis para enunciar el primero y el segundo de los grandes objetivos. La meta inicial fue "credibilidad, credibilidad, credibilidad". La nueva es "crecimiento, crecimiento, crecimiento"."
\end{abstract}

\begin{abstract}
"Es posible actuar en varios frentes para estimular tanto el consumo como la inversión productiva y poner en marcha la recuperación de la economía. No será preciso, para eso, adoptar una política monetaria irresponsable, ni descuidar las cuentas públicas. Cualquier política imprudente llegaría a un impasse en poco tiempo, porque afectaría la credibilidad del gobierno y causaría inestabilidad financiera." 13
\end{abstract}

Así, el periódico priorizaba el desarrollo de políticas para afianzar la "seguridad económica" y preservar la "estabilidad", evitando definiciones "irresponsables", que podrían tener costosas consecuencias para el gobierno y el sistema económico. De esta forma, comenzaría a reforzarse una definición ya adoptada de forma posterior a las elecciones de 2002, la cual se man-

12 03/06/2003 "La tasa de interés y los usos del oficio"

13 05/07/2003, "Sin inflación, hay espacio para crecer". 
tendría de forma constante durante las tres coyunturas: aquella que enfatizaba sobre las "consecuencias negativas" que se producirían de escogerse políticas alternativas a la preservación de la "austeridad fiscal".

O ESP señalaba lo peligroso que resultaría para el ingreso de inversiones externas no darle importancia a los contratos, así como tener relaciones por parte del gobierno con los movimientos sociales. ${ }^{14}$ De esta forma, con la sobreestimación de las consecuencias negativas que podrían sobrevenir de las definiciones "irresponsables", el periódico pretendía influir en las decisiones económicas del gobierno. O ESP, que se expresaba como representante de los "agentes financieros", sostenía que la estabilidad económica -que había sido respetada por la austeridad fiscal del gobierno- se encontraría amenazada por los lazos del gobierno con el MST y sus dificultades para aprobar la reforma de la Jubilación.

El periódico retomaría sus exigencias de una política económica "responsable" con motivo del envío al Congreso del presupuesto federal para $2004^{15}$. Así, apelaría de forma reiterada a una sobreestimación de las consecuencias negativas que se producirían en caso de que el gobierno se extraviara del camino de la denominada "austeridad fiscal". En síntesis, el periódico aprobaba el rumbo económico escogido por el gobierno mientras no aparecieran los signos de medidas alternativas a sus expectativas. Por ello, aspiraba a naturalizar (Barthes, 2004) el valor de la estabilidad económica, señalando de forma reiterada que cualquier alternativa conduciría de forma automática a la crisis y al desastre económico.

El mismo argumento de la naturalización de la estabilidad económica y de las consecuencias negativas que existirían en caso de apartarse de la austeridad fiscal, sería utilizado a la hora de recomendar una renovación del acuerdo con el FMI para el siguiente año de 2004:

\footnotetext{
“Brasil está en el rumbo adecuado y la política económica va bien, pero el País continúa vulnerable a los cambios de humor en los mercados. La advertencia fue hecha por el Fondo Monetario Internacional (FMI), en la relatoría sobre Perspectivas Económicas Mundiales, y reiterada por el economista-jefe de la Institución, Kenneth Rogoff, en una entrevista en Dubái.
}

14 01/08/2003, "Más espacio para el gasto público" 15 25/08/2003, "Presupuesto y credibilidad". 
Este aviso es puro buen sentido. No es hora de relajar la política fiscal ni de abandonar el programa de reformas. Crecimiento seguro el País solo va a tener cuando esté menos sujeto a las oscilaciones y la desconfianza de los mercados. El ministro de Fazenda, Antonio Palocci, ha mostrado que entiende ese dato simple. El presidente Luis Ignacio Lula da Silva ha apoyado, hasta ahora, la prudencia fiscal. Pero hasta en el gobierno hay presiones muy fuertes para el cambio de rumbo y es preciso continuar resistiendo." ${ }^{16}$

El periódico, mediante la reiterada sobreestimación de la amenaza ${ }^{17}$ de las consecuencias negativas que tendría un relajamiento en la austeridad fiscal, presentaría la renovación del acuerdo con el FMI como aquello que garantizaría la continuidad de la estabilidad económica, obviando las restricciones para la elaboración de políticas más autónomas que un acuerdo de estas características suponía. Mediante esta argumentación, se pretendía ejercer un veto hacia posibles alternativas al rumbo económico que era presentado como garante de la estabilidad. Esto último era complementado con el señalamiento de que sólo mediante la conservación de "la credibilidad financiera y la consolidación de la estabilidad" sería posible realizar los objetivos igualitaristas identificables con las exigencias del PT.

Durante el período del Mensalão, de los 26 editoriales referidos a cuestiones económicas, 14 (53\%) referían a la necesidad de incrementar la austeridad fiscal como forma de contrapesar los efectos de la crisis política, 7 (26\%) exigían una reducción de los gastos públicos y la carga tributaria, y 5 (19\%) estaban orientados a criticar la supuesta incapacidad administrativa del gobierno.

Frente a los efectos negativos hacia el capital político del gobierno que estaba produciendo la crisis política del mensalão, el periódico señalaba que se podría sostener un contrapunto frente a estas dificultades si desde la

16 23/09/2003, "Los elogios y la advertencia del FMI"

17 Fonseca ha desarrollado este concepto como elemento característico de la ideología de O ESP: “la comparación de la realidad brasileña, en lo que desagrada al periódico, con momentos históricos tales como la Revolución Francesa, la Revolución Rusa y el Nazismo, es un recurso bastante utilizado sobre todo en momentos candentes, como el caso del Plan Cruzado, y forma parte de una estrategia retórica e imaginaria bien articulada. De la misma forma, el fantasma del socialismo es utilizado, pero de forma todavía más continua. El uso abundante de esas imágenes constituye un modus operandi de los editoriales de $\operatorname{OESP}(. .$.$) . La lógica que permea tal estrategia implica, como se observa, sobreestimar$ a los adversarios -acciones, grupos, instituciones- y su potencial destructivo, otorgándole así una enorme gravedad a una determinada situación." (Fonseca, 2005; 182) 
dirección económica se mantenían la austeridad fiscal, la seguridad para las inversiones y la aprobación de medidas para dinamizar la economía ${ }^{18}$. Esta posición del periódico representaba una pretensión de cooptación ante la crisis, al sugerir O ESP salidas posibles de acuerdo a sus conservadores intereses en materia económica, aprovechando la debilidad política del gobierno. La solución que O ESP sugería en materia económica para afrontar estas dificultades sería un "blindaje de la economía contra los efectos de la inestabilidad política”"19, el cual suponía preservar las políticas económicas de cuño ortodoxo. De forma elogiosa, el periódico señalaba las diferencias que existirían entre la gravedad de la crisis política, y una economía que no parecía expresar los signos de esta gravedad. El periódico exigía, en este contexto, priorizar las metas de inflación y la continuidad de la austeridad fiscal por sobre "políticas irresponsables de crecimiento ${ }^{20}$.

Se criticaba así a los sectores gubernamentales que reclamaban cambios económicos frente a la crisis, señalando que:

\begin{abstract}
"Ni la evidencia cristalina de que Brasil tiene hoy una economía más fuerte que la crisis política -gracias a un trabajo de construcción institucional iniciado antes del ascenso de Lula, como Palocci tuvo la elegancia de recordar en la entrevista del domingo- disuade a muchos petistas de la convicción de que es preciso dar marcha atrás en un proceso claramente exitoso, la solitaria joya de este gobierno sin corona, que acumula más errores hasta de lo que se esperaba, dada la falta de preparación del presidente y su indiferencia para administrar. Los que desean apagar la única luz que no titila en la gestión del País argumentan que la ética en el PT fue arrastrada agua abajo por la ‘traición' a las viejas creencias del partido." ${ }^{21}$
\end{abstract}

"Todo eso ocurre en el momento en que una grave crisis política se mezcla con los primeros movimientos de preparación de las campañas electorales de 2006. La estabilidad económica de Brasil, todavía no comprometida por la turbulencia política, depende en alto grado de la capacidad del gobierno de mantener la austeridad y la solvencia del Tesoro. Si el cerco al gobierno afecta esas

18 09/06/2005, “Crisis y oportunidad".

19 26/06/2005, "El realismo del CMN"

20 07/08/2005, "Un rumbo para el gobierno"

21 25/08/2005, "La diferencia y la corrupción” 
condiciones, el costo para el País podrá ir mucho más allá de un desajuste presupuestario." 22

El periódico criticaría las posibilidades del gobierno de abandonar la prudencia fiscal, en tanto éste parecía dar importancia a las exigencias "corporativas" frente a la crisis. O ESP acusaba así a quienes reclamaban cambios en la política económica de querer destruir el único logro de este gobierno, la "solitaria joya de este gobierno sin corona", aumentando las posibilidades de una crisis económica.

Durante este período y el anterior, la defensa de la austeridad fiscal estaría asociada por parte del periódico al resguardo del Ministro de Fazenda Antonio Palocci, como figura que representaba a nivel gubernamental una visión coincidente con las expectativas de preservar la ortodoxia económica: "Ese es el sentido de una advertencia del ministro, que vale más para el presidente de la República que para el mercado financiero: enflaquecer la política económica 'sería un gran engaño, un engaño del tamaño de Brasil"'. ${ }^{23}$ De este modo, en la medida en que el periódico asociaba la política de austeridad fiscal a la dirección económica de Palocci, identificaba las acusaciones de corrupción dirigidas hacia el ministro con una situación que podría alterar el curso de la economía. Realizaba así una defensa de su competencia como funcionario y de las políticas ejecutadas en materia económica.

Por otra parte, como hemos referido, un porcentaje de los editoriales estaría abocado a exigir una administración más competente y una reducción del gasto público. ${ }^{24}$ El periódico reclamaba por una "reducción de la insoportable carga tributaria", así como criticaba los "excesivos" tributos del Estado hacia lo que denominaba como el "sector productivo" 25 . Como hemos señalado, durante este período la crítica también se centraría en lo que se percibía como una baja capacidad administrativa del gobierno:

“De modo general, falta más competencia para administrar políticas que dinero para invertir. El PT llegó al gobierno con la promesa de implantar políticas de crecimiento económico y de creación

22 22/08/2005, "Costos de la crisis".

23 El 23/08/2005, con motivo de las acusaciones a Palocci que pusieron en cuestión su función ministerial, el periódico publicó un editorial titulado "El ejemplo de Palocci”.

24 06/06/2005, "Shock de gestión"

25 16/08/2005, "Pesado e ineficiente" 
de empleos. Pretendía, por lo menos en la propaganda, recuperar para el Estado un papel de liderazgo en el desarrollo. En la práctica, quedó lejos de eso. El gobierno consiguió sorprender con una política fiscal muy seria y con una política monetaria de gran severidad, pero falló en casi todo el resto.”26

El periódico, que resultaba crítico de la distribución y el volumen de los gastos del gobierno, así como de su supuesta inoperancia administrativa, abogaba por una mayor apertura económica que, según esta visión, mejoraría la competitividad y eficiencia empresariales, favorecería a los consumidores y modernizaría la economía. ${ }^{27}$ A partir de esta invalidación centrada en el exceso de gastos gubernamentales, O ESP se acercaría hacia finales del período a una crítica que sería profundizada durante las elecciones de 2006:

\footnotetext{
"Si el gobierno decidiera luchar por un plan fiscal de largo plazo, en este momento, transmitiría al País y al mundo el mejor mensaje posible a vísperas de una campaña electoral. La resistencia a una propuesta de ese tipo envía un mensaje opuesto: frente a las elecciones, Brasilia hasta podrá buscar un superávit primario de $4,25 \%$ pero sin dar una mínima atención a la calidad del gasto público. La ejecución del presupuesto tendrá objetivos electorales y cualquier sobrante financiera creada por el crecimiento económico será usada para atraer alianzas políticas. Si esa no fuera la idea del presidente, tendrá que actuar con rapidez para deshacer la impresión de sí que lo es." ${ }^{28}$
}

En el período correspondiente a las elecciones de 2006, 48 editoriales fueron dedicados a materia económica. De esos 48 editoriales, 28 (58\%) estarían dedicados a exigir un corte en los gastos públicos y una reducción de la carga tributaria como forma de no caer en gastos electorales. 9 (19\%) editoriales serían dedicados a realizar una crítica sobre los efectos en el electorado que produciría el programa de transferencia de ingresos Bolsa Familia. Por otra parte, 5 (10\%) editoriales estarían referidos a señalar la reiterada contraposición entre una política económica responsable y una política económica irresponsable. Finalmente, 4 (8\%) editoriales estarían dedicados

26 28/09/05, "Se precisa de gerentes"

27 10/10/2005, "Reformas, no protección”.

28 28/10/2005, "Señales de gastos". 
a reiterar la crítica a la incapacidad administrativa del gobierno, así como otros $2(4 \%)$ a la defensa de una privatización de las empresas estatales.

Como hemos señalado recién, un reclamo importante en el enfoque económico del período por parte de O ESP, sería la exigencia hacia el gobierno de "osadía para cortar" los gastos:

"La palabra osadía es perfectamente adecuada. Si no pone un freno al crecimiento de los gastos públicos, especialmente a los costos presupuestarios, el gobierno jamás conseguirá alinear al Brasil a las economías más dinámicas. Si el crecimiento brasileño continúa debajo de la media mundial (...) Es porque la economía nacional continúa oprimida por el peso excesivo de un gobierno obeso y de apetito insaciable." 29

Así, las críticas del periódico al exceso de gastos y la amplitud de la administración gubernamental serían fundamentales durante este período. Asimismo, se exigiría al gobierno reafirmar su compromiso con una austeridad fiscal todavía no consolidada y no ceder a un relajamiento fiscal por tentaciones electorales. Este señalamiento se debía a la percepción por parte de O ESP de que en lugar de aprovechar esta fase para el "crecimiento seguro", el gobierno podría estar incrementando los gastos. ${ }^{30}$ Frente a esta situación, se sugería realizar reformas que corrigieran la ineficiencia en los gastos, dada la pesada carga tributaria que no permitiría a las empresas y las familias invertir y consumir. ${ }^{31}$

A partir de este período, se haría visible el cambio en la percepción del periódico respecto de la política económica, con la renuncia de Palocci y la asunción de Mantega ${ }^{32}$ como nuevo Ministro de Fazenda. El periódico señalaba que el exceso de gastos del gobierno con la maquinaria administrativa-estatal comprometía la capacidad de crecimiento de la economía:

"En verdad, aquí, además de haber voracidad fiscal, se gasta mal el dinero del contribuyente. Es preciso tener en cuenta ese hecho cuando se discute la enorme carga tributaria brasileña. El problema no está solamente en el peso total de impuestos y contribucio-

29 17/05/2006, “Osadía para cortar”

30 23/05/2006, “El peligro que viene de afuera”.

31 19/06/2006, "Propuesta insensata"

32 Este cambio se produciría el 27 de marzo de 2006 con la asunción de Guido Mantega como nuevo Ministro de Fazenda. 
nes extraídas anualmente de la producción nacional. El prejuicio es doble. De un lado, se retiran de la economía recursos necesarios para la inversión privada, la producción y el consumo. Del otro, buena parte de ese dinero es triturada en gastos improductivos o de bajísimo retorno para la gran masa de la población (...) No hay alternativa saludable, por lo tanto, a una seria política de contención de gastos del sector público."33

El periódico criticaba así lo que percibía como los excesivos gastos del gobierno con el propósito de sostener la "hinchada máquina pública". ${ }^{34} \mathrm{Con}$ forme se iría produciendo el acercamiento de las elecciones 2006, O ESP incrementaría sus críticas al gasto público gubernamental, señalando a éste como un ejercicio de pretensiones electorales para retener votantes. De este modo, aparecería la crítica al problema a futuro que planteaba elevar los salarios de los funcionarios públicos, orientado esto según O ESP por conveniencias electorales. ${ }^{35}$ Estos "excesivos gastos" en los funcionarios públicos del gobierno, serían interpretados como consecuencia de que "la política de personal del gobierno Lula está sobre el comando de los sindicatos":

“El gobierno no solamente elevó el número de empleados, interrumpiendo la trayectoria de reducción que se observaba desde el inicio de la década pasada, sino que pasó a negociar la concesión de aumentos diferenciados y generosos con dirigentes sindicales de las carreras de funcionarios (...) Es poco probable que, si es reelecto, el presidente modifique la actual política, pues la utiliza para conquistar prestigio y votos y no demostró haber comprendido los riesgos que ésta impone." 36

Según el periódico, la política de gastos del gobierno Lula involucraría la contratación de funcionarios públicos y las bonificaciones salariales, así como las políticas sociales, que tendrían por efecto garantizar la cooptación de sectores del electorado, seducidos por las "bondades estatales". ${ }^{37} \mathrm{En}$ esta secuencia, el programa Bolsa Familia ${ }^{38}$, que comenzaba a evidenciar sus

33 26/08/2006, "La economía sofocada”.

34 29/09/2006, "La eterna lección de Garrincha”

35 11/09/2006, "Más gastos con la hoja”

36 03/08/2006, "Los riesgos del descontrol”.

37 20/06/2006, "De lo principal no se habla"

38 "la más importante de las políticas sociales fue, sin duda, el programa Bolsa Familia, 
efectos redistributivos en el período de la campaña electoral de 2006 (Singer, 2009), sería otro de los aspectos criticados por el periódico. O ESP haría referencia a los efectos de la política social del Bolsa-Familia como la "más poderosa arma reelectoral de Lula":

\begin{abstract}
"El avance en relación al viejo asistencialismo clientelista es de la noche para el día. ¿Pero a qué viene todo ese progreso? El término recurrente es combate a la pobreza. Pero la expresión correcta es sustentación de la pobreza. El Bolsa Familia y los programas semejantes sin duda tornan la pobreza un tanto más soportable, cuando no salvan literalmente vidas pobres. Ayudan a disminuir la desigualdad del ingreso, pero no modifican la penosa condición de los pobres. Haga lo que haga por la calidad de vida de sus atendidos, el verdadero Ejército de Salvación movilizado por el gobierno no tiene como darles los medios para dejar de ser lo que son." 39
\end{abstract}

“(...) Ahí está, precisamente, la distorsión mayor -aunque no inédita en la historia política del País, infelizmente- de la conciencia de la ciudadanía que motiva el voto popular. En el pasado eran las obras públicas hechas sobre la hora en vísperas de los comicios, para atraer votos. Hoy es el dinero sonante dado, directamente, a aquellos llevados a encarar la adhesión electoral como medio de supervivencia. Es el triunfo que 'mata' todas las 'manos' de cualquier adversario, por más bien diseñada que sea su campaña." ${ }^{40}$

Estos editoriales demuestran el modo en que el periódico comenzaba a percibir la importancia del programa social en las apreciaciones del electorado brasileño. Se descalificaba el Bolsa Familia como un garante de la

que resultó de la unificación de cuatro programas de transferencia condicionada de ingresos creados en el gobierno de Fernando Henrique Cardoso. La decisión de unificarlos y transformarlos en el vagón principal de las acciones del gobierno en el área social ocurrió después de la breve y fracasada experiencia del programa Fome Zero, basado en la idea de fomentar la agricultura familiar por la distribución local de alimentos a la población carente, que había sido una de las principales banderas electorales del candidato Lula. (...) Creciendo en el número de beneficiados y el volumen de recursos transferidos, el Bolsa Familia desempeñó un papel importante en la reducción de la pobreza, en especial en el Nordeste, y contribuyó para consolidar la amplia mayoría electoral de Lula en la región." (Fausto S., 2012; 534).

39 23/06/2006, "Sustentación de la pobreza".

40 01/09/2006, “El triunfo que 'mata' todas las 'manos”" 
reproducción de la situación de los pobres en favor del gobierno, que se beneficiaría con los votos de los asistidos. Éste programa social serviría para sustentar la pobreza, pero no para sacar a los pobres de su situación estructural, lo que beneficiaría al candidato Lula. En palabras del periódico, esta política "no modifica la posición social, pero contribuye decisivamente para el saco de votos del presidente." ${ }^{41}$ Como vemos, el programa social sería percibido como otra de las manipulaciones/engaños del gobierno lulista promovida hacia los sectores populares, que preservaría los votos del electorado como "forma de supervivencia".

Finalmente, el periódico se dedicaría a señalar las consecuencias negativas que en términos económicos se producirían en caso de que el presidente Lula lograra la reelección: “Más gastos y más impuestos: esta es la perspectiva anunciada a los brasileños por el gobierno central, en el caso de una reelección del presidente Luis Ignacio Lula da Silva." 42

O ESP, que criticaba el exceso de gastos públicos, la excesiva "carga tributaria” y la burocratización excesiva del gobierno, ${ }^{43}$ auguraba más impuestos y menos espacio para el sector privado, así como una ampliación del gasto público en caso de que Lula obtuviera la reelección:

\begin{abstract}
"La retórica del presidente Lula sobre el nirvana al cual habría hecho ascender la economía brasileña convence innegablemente a los electores cuyo nivel educacional es igual o inferior al suyo. No convence, sin embargo, a los agentes económicos, los inversores y socios comerciales, y mucho menos analistas, nacionales y extranjeros, que tienen ojos para ver las señales cada vez más densas de una realidad inquietante."
\end{abstract}

\footnotetext{
"Considerando todo esto, no sorprende que el Banco Mundial, el FMI y también el más difundido periódico económico del mundo, el Financial Times (FT), adviertan un futuro sombrío para Brasil. Sobra dinero para inversiones en el mundo, constata el FT, pero los que lo tienen están reticentes en relación a Brasil: ellos simplemente dudan que un Lula reelecto hará las reformas imprescindibles para restringir el gasto público y por eso van a buscar puertos más atrayentes para sus capitales. Lo que se teme allá fuera es
}

41 30/06/ 2006, "Lamentación de fachada"

42 29/08/2006, "Primera promesa no cumplida".

43 30/08/2006, "Burocracia de más". 
que, si Lula es reelecto, su próximo gobierno degenere hacia una política populista." 44

Vemos entonces cómo una de las argumentaciones fundamentales de O ESP durante la campaña residía en construir nuevamente una sobreestimación de la amenaza sobre el riesgo de que, en caso de que el presidente Lula fuese reelecto, sobrevenga una "política populista" que pusiera en riesgo el modelo de "estabilidad económica" naturalizado por el periódico.

\section{CONCLUSIONES}

A partir del estudio de estos 91 editoriales, hemos podido analizar la transición que se produciría en la percepción del periódico sobre la política económica del primer gobierno de Lula. Esta se manifestaría en el cambio de la legitimación inicial de la austeridad fiscal del gobierno como capaz de preservar la "estabilidad económica", hacia la crítica posterior, centrada en: el exceso de gasto público, el "asistencialismo electoralista" del Bolsa Familia, así como en el augurio de la política económica "populista" que sobrevendría en caso de que Lula venciera en los comicios de 2006.

La percepción del periódico sobre la política económica sería coincidente con la percepción general de O ESP respecto del gobierno de Lula, considerando que esta última pasaría, como hemos señalado (Goldstein, 2013), de la expectativa inicial a la confrontación a partir de la irrupción del escándalo del "mensalão" en 2005. Esta transición resulta visible en el siguiente cuadro, donde las dos primeras columnas del gráfico manifiestan una valoración positiva y las restantes una negativa, dando cuenta de la variación en los encuadramientos del periódico sobre la política económica con el paso de los períodos:

44 15/09/2006, "La retórica no esconde la realidad". 


\section{Editoriales sobre Política Económica}

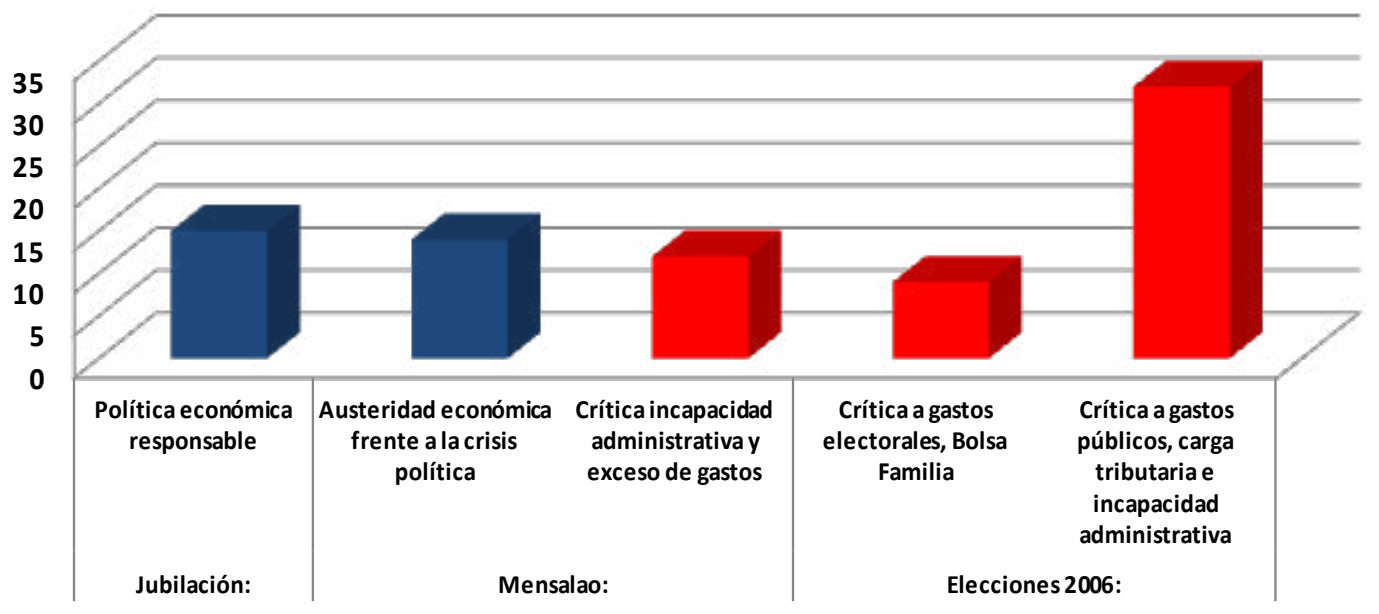

La mirada liberal-conservadora del periódico, que encontraba en la cuestión económica uno de los núcleos estructuradores de su discurso, evaluaría de acuerdo a esta cosmovisión los cambios en las definiciones económicas adoptados por el gobierno. En este sentido, como hemos señalado, mientras que en el primer tramo las directivas del gobierno en materia económica definidas de forma ortodoxa por Antonio Palocci coincidirían con el naturalizado modelo de "estabilidad económica" defendido por el periódico, a partir de su renuncia en marzo de 2006 y con el nombramiento de Guido Mantega, la adopción gubernamental de una mayor intervención estatal en el desarrollo económico (Fausto, 2012) sería asociada al exceso de gastos y la pérdida de la austeridad fiscal por O ESP.

Como resulta visible, el cambio de ministros y de directivas a este aparejado, resultaría un momento importante en la transición en la evaluación de O ESP sobre la política económica gubernamental. Esta transición en la percepción del periódico, de la legitimación de la ortodoxia de Palocci a comienzos del gobierno, a la crítica del desarrollismo de Mantega en 2006, ha resultado el objeto de estudio que este trabajo ha aspirado a comprender.

\section{BIBLIOGRAFÍA}

Ansart, Pierre (1983): Ideología, conflictos y poder, Premiá, Puebla.

Azevedo, Fernando (2008): Imprensa, Partido dos Trabalhadores e eleições presidenciais (1989-2006), presentado en el XVII encuentro COMPÓS: San Pablo.

Barthes, Roland (2004): Mitologías, Siglo XXI, Buenos Aires. 
Bezerra de Paiva, Uilson (2006): O governo de Luiz Inácio Lula da Silva e o MST em O Estado de S. Paulo em 2003: estudo de elementos da ação política do jornal. San Pablo. Disertación de Maestría en la Escuela de Comunicaciones y Artes (ECA) de la Universidad de San Pablo (USP).

Boelhouwer Menezes, Daiane: “A retórica da intransigência brasileira: mídia e política no primeiro governo de Lula” en Civitas - Revista de Ciências Sociais, v. 8, n. 2, 2008.

Borrat, Hector (1989): El periódico, actor político, Gili, Barcelona,.

Capelato, Maria Helena y Prado, Maria Lígia (1980): O Bravo Matutino: Imprensa e ideología no jornal "O Estado de S. Paulo”, Editora Alfa-Omega, San Pablo.

Conti, Mario (1999): Notícias do Planalto: a imprensa e Fernando Collor, Companhia das Letras, San Pablo.

Fausto, Sergio (2012): “Modernização pela via democrática” en Historia do Brasil (comp. Boris Fausto), texto inédito cedido por el autor.

Fonseca, Francisco (2005): O consenso forjado: a grande imprensa e a formação da Agenda Ultraliberal no Brasil, Editora Hucitec: São Paulo.

Gamson, William y Modigliani, Andre (1989): “Media Discourse and Public Opinion on Nuclear Power: A Constructionist Approach" en American Journal of Sociology, Vol. 95, No. 1, pp. 1-37

Goldstein, Ariel y Comellini, Sebastián (2012): Medios y política en América Latina: una comparación entre las elecciones del Brasil 2006 y el Perú 2011 en Question, vol. 1, La Plata.

Goldstein, Ariel (2013): De la expectativa a la confrontación: O Estado de S. Paulo durante el primer gobierno de Lula da Silva, Tesis de Maestría, Instituto de Altos Estudios Sociales (IDAES), Universidad Nacional de San Martín (UNSAM).

Miguel, Luis y Aline de Almeida, Coutinho (2007): “A crise e suas fronteiras: oito meses de ‘mensalão' nos editoriais dos jornais” en Opinião Pública, Campinas, vol. 13, n 1, Junho, p.97-123.

Montoya Londoño, Catalina (2011): Framing event-driven news: the promotion of the US Agenda in the colombian armed conflict trough the pages of El Tiempo newspaper, Editorial Pontificia Universidad Javeriana, Bogotá.

Nunomura, Eduardo (2012): O mensalão impresso o escândalo político-midiático do governo Lula nas páginas de Folha e Veja, Disertación de Maestría, Escuela de Comunicaciones y Artes (ECA), Universidad de San Pablo (USP).

Pilagallo, Oscar (2012): Historia da imprensa paulista: jornalismo e poder de D. Pedro a Dilma, Tres Estrelas, San Pablo.

Porto, Mario (2002): “Enquadramentos da mídia e política”, Trabajo presentado en el XXVI Encontro Anual da Associação Nacional de Pós-Graduação e Pesquisa em Ciências Sociais - ANPOCS, Caxambu/MG, Brasil, 22 a 26 de octubre de 2002.

Sader, Emir (2010): “Brasil, de Getúlio a Lula" en Brasil, entre el pasado y el futuro, Emir Sader y Marco Aurelio García (comps.), Capital Intelectual, Buenos Aires. 
Sader, Emir (2013): “A construção da hegemonia pós-neoliberal” en Sader, Emir y Gentili, Pablo (comps.) 10 anos de governos pós neoliberais no Brasil: Lula e Dilma, Boitempo, San Pablo.

Singer, André (2009): “Raízes Sociais e Ideológicas do Lulismo” en Novos Estudos Cebrap, $\mathrm{n}^{\circ} 85$, pp. 83-102, Noviembre.

Secco, Lincoln (2011): Historia do PT, Atelié Editorial, San Pablo.

Verón, Eliseo (1987): “La palabra adversativa”, en El Discurso Político, Hachette, Buenos Aires.

Werneck, Paulo (2012): “Cientista político André Singer explica sua tese sobre o lulismo" en Folha de São Paulo, Agosto 19, Ilustrissíma. Disponible en: http://www1.folha.uol.com. br/ilustrissima/1139728-cientista-politico-andre-singer-explica-sua-tese-sobre-o-lulismo. shtml

\section{Ariel Alejandro Goldstein}

Sociólogo (UBA). Becario del Conicet de Posgrado en el Instituto de Estudios de América Latina y el Caribe (lealc, Facultad de Ciencias Sociales, UBA). Doctorando en Ciencias Sociales (FSOC-UBA). Docente en "Política Latinoamericana", Carrera de Ciencia Política, Facultad de Ciencias Sociales, UBA. 